\title{
PRÁTICAS DISCURSIVAS E O SILENCIAMENTO DO DOENTE MENTAL: SEXUALIDADE NEGADA?
}

\author{
Discursive Practices and Silence of the \\ Mental Patient: Denied Sexuality? \\ Las Prácticas Discursivas y Silencio del \\ Paciente Mental: ¿Sexualidad Negada?
}

Francisco Arnoldo Nunes de Miranda ${ }^{1}$

Antonia Regina Ferreira Furegato ${ }^{2}$

Dulcian Medeiros de Azevedo 3

\begin{abstract}
Resumo
0 estudo teve por objetivo identificar as Representações Sociais dos profissionais enfermeiros sobre a sexualidade do doente mental. Trata-se de uma pesquisa de natureza exploratório-descritiva, com abordagem qualitativa. Utilizou-se 0 recurso técnico-metodológico denominado Técnica de Investigação em Situações Cotidianas (TSC), aplicado aos 17 enfermeiros que trabalhavam em serviços psiquiátricos de Ribeirão Preto/SP. Através das manifestações discursivas, verificou-se que 0 profissional enfermeiro nega a sexualidade do doente mental, como uma forma de silêncio, estabelecendo limites para a censura sobre essa questão. Nesta perspectiva, ocorre o silenciamento sobre a sexualidade do doente mental, estabelecendose uma política do sentido sobre o mesmo. Tal posicionamento revela a estratégia adotada sobre esse saber e poder, cumprindo as determinações do seu estatuto profissional que é ir ao encontro às expectativas institucionais e sociais.
\end{abstract}

Palavras-chave: Saúde Mental. Sexualidade. Pessoas Mentalmente Doentes. Enfermagem Psiquiátrica. Pesquisa Qualitativa.

\begin{abstract}
The study's objective was to identify the professionals nurses's Social Representations about the sexuality of the mental patient. It is a research of exploratory-descriptive nature, with qualitative approach. The resource technicianmethodological used denominated Technique of Investigation in Daily Situations (TSC), applied to 17 nurses that worked in psychiatric services of Ribeirão Preto/SP. Through the discursive manifestations, was verified that the professional nurse denies the sexuality of the mental patient, as a silence form, establishing limits for the censorship on that subject. In this perspective happens the silentness about the sexuality of the mental patient, settling down a politics of the sense on the same. Such positioning reveals the strategy adopted on that knowledge and power, accomplishing the determinations of your professional statute that it is to go to the encounter to the institutional and social expectations.
\end{abstract}

Keywords: Mental health. Sexuality. Mentally III Persons. Psychiatric Nursing. Qualitative Research.

\section{Resumen}

El objetivo del estudio fue identificar la Representaciones Sociales en profesionales enfermeros sobre la sexualidad del paciente mental. Es una investigación de naturaleza exploratorio-descriptiva, con el acercamiento cualitativo. El recurso usado fue la Técnica Investigación en las Situaciones Diarias (TSC), aplicada a 17 enfermeros que trabajaron en los servicios psiquiátricos de Ribeirão Preto/SP. En las manifestaciones discursivas, se verificó que la enfermera niega la sexualidad del paciente mental, como una forma de silencio, estableciendo los límites para la censura en ese asunto. En esta perspectiva, pasa el silenciamiento sobre la sexualidad del paciente mental, mientras estableciendo abajo una política del sentido adelante el mismo. El tal posicionamiento revela la estrategia adoptada en ese conocimiento e impulsa, mientras logrando las determinaciones de su estatuto profesional que es ir al encuentro a las expectativas institucionales y sociales.

Palabras clave: Salud Mental. Sexualidad. Enfermos Mentales. Enfermería Psiquiátrica. Investigación Cualitativa.

$\overline{1}$ Doutor em Enfermagem, Docente da Graduação e do Programa de Pós-Graduação em Enfermagem, Universidade Federal do Rio Grande do Norte - PGENF-UFRN. E-mail: farnoldo@gmail.com. ${ }^{2}$ Professora Livre-Docente da Escola de Enfermagem de Ribeirão Preto, Universidade de São Paulo - EERP/USP. ${ }^{3}$ Professor Substituto do Departamento de Enfermagem - UFRN. Mestrando em Enfermagem, PGENF-UFRN. Bolsista CAPES. 


\section{INTRODUÇÃO}

0 exercício da enfermagem está inserido num contexto abrangente. 0 caráter dessa profissão, às vezes convergente, múltiplo, heterogêneo, conflitivo, ambivalente, afetivo e valorativo, projeta uma infinidade de questionamentos. Como elemento catalisador do atendimento ao portador de transtorno mental, 0 enfermeiro é o profissional que detém melhor conhecimento da estrutura e da dinâmica do serviço, nas suas 24 horas.

0 enfermeiro conhece as múltiplas facetas da realidade institucional; entretanto, não sabendo como utilizar produtivamente esse conhecimento, enfrenta situações de desgaste físico e emocional. Lidar com a sexualidade faz parte das atividades que, embora não explicitadas oficialmente, permeiam todas as ações e comportamentos desse profissional, enquanto exigência para desempenhar seu papel e ser socialmente aceito.

Pretendendo-se responder a alguns dos questionamentos sobre o exercício da enfermagem psiquiátrica no seu cotidiano, objetivamos identificar, mediante a análise do discurso, as representações sociais dos profissionais enfermeiros sobre a sexualidade do portador de transtorno mental, nos serviços de saúde mental e assistência psiquiátrica.

0 estudo apresentado é um recorte originário da dissertação de mestrado da Escola de Enfermagem de Ribeirão Preto, Universidade de São Paulo'.

\section{POSTURA TEÓRICO-METODOLÓGICA}

A Teoria das Representações Sociais (TRS) constitui um modo particular de observação sobre um fato, fenômeno, pessoa ou assunto em destaque, a qual amplia as possibilidades metodológicas, mediado pela linguagem, verbal ou não-verbal, incluindo o silêncio².

Na linguagem verbal cotidiana, o silêncio não está disponível à visibilidade por não ser diretamente observável. Ele passa pelas palavras e não dura. Só é possível vislumbrá-lo, de modo fugaz, através dos gestos, expressões faciais, do não-dito, do indisível, pois já está posto. Da mesma forma, escrever é uma relação particular com o silêncio. Portanto, o silêncio não é a ausência de palavras, mas o que há entre as palavras, entre as notas musicais, entre as linhas, entre os astros, entre os seres ${ }^{3}$.

A atenção da articulação entre gesto e silêncio, enquanto expressividade e gestualidade, também está orientada pela fala. Assim, o homem exerce o seu controle e sua disciplina fazendo o silêncio falar ou, ao contrário, supondo poder calar o sujeito ${ }^{3}$.

Destarte, quando não falamos, não estamos apenas mudos, estamos simplesmente em silêncio, pois no silenciamento há o pensamento, a introspecção, a contemplação, dentre outras formas de silenciar.

Por sua natureza, o silêncio não é representável tal como concebido pelas teorias da linguagem, sendo necessário deslocar a análise do domínio dos produtos para o dos processos de produção dos sentidos, uma vez que os métodos tradicionais são a própria negação do silêncio como matéria significativa, diferente e específica ${ }^{3}$. Entende-se que a negação da sexualidade do doente mental está circunscrita pela política do silêncio que se tornará familiar pela TRS.
Esta teoria procura dar conta de um fenômeno, sobretudo urbano, em que o homem manifesta sua capacidade inventiva para assenhorar-se do mundo por meio de conceitos, afirmações e explicações originadas no dia-a-dia, durante interações sociais, a respeito de qualquer objeto, social ou natural, para torná-lo familiar e garantir a comunicação no interior do grupo de pertença e com as demais pessoas extragrupos ${ }^{2}$.

As representações sociais levam em conta os dados internos e externos do contexto real e imaginado, quer individual, quer coletivo, de uma dada realidade social, apresentando-se como um corpus (des)organizado de conhecimentos, acessível através da atividade psíquica, esta, portanto, não perceptível e inteligível a partir da realidade física e social do dia-dia, a não ser pelo recurso lingüístico decorrente da comunicação por ser uma ligação contínua de trocas e uma maneira de liberar a imaginação, ou seja, sobre o que se pensa, o que sabe, porque sabe e para que sabe sobre um determinado objeto $0^{1,2}$.

As representações sociais produzem, determinam e explicam comportamentos através dos quais é possível definir a natureza dos estímulos e o significado das respostas. Determinam comportamentos, comunicações interindividuais e ações que podem decifrar, predizer e antecipar muitos atos dos sujeitos no seu contexto psicossocial ${ }^{1,2}$.

As representações sociais também revelam conflitos normativos, materiais e sociais, definindo o senso-comum, mediante instrumentos da comunicação interindividual, intra-individual e intra-institucional.

Dessa forma, o homem em sua cotidianidade, diante da informação, resume, recorta e classifica os conteúdos necessários a sua interação social, assim como também silencia sobre aspectos desse mesmo objeto. Nesta perspectiva, em que momento da trajetória humana a loucura e o sexo se aproximam e como influenciam a prática da enfermagem e seu silenciamento?

No ocidente, o sexo é encarado como um evento natural, cuja base instintiva prioriza o aspecto biológico, onde suas manifestações estão sujeitas à repressão $0^{4}$. A compreensão das práticas discursivas sobre a loucura e a sexualidade pode ser entendida sob diversos domínios conceituais, os quais remetem ao corpo humano e às suas manifestações corporais, gerando, em alguns casos, posições inseridas na natureza do não-dizível, ou seja, da censura.

Nesta perspectiva, o corpo humano pode ser concebido através da noção médica (anatomofisiológica), neurológica (esquema corporal) e psicológica (consciência corporal e imagem corporal). Todas se apresentam revestidas de conhecimento oriundo da reificação da ciência e do senso comum ${ }^{5}$.

Portanto, a sexualidade e a loucura, assim como o portador de transtorno mental, passam a ser avaliados mediante suas manifestações corporais e compartimentais, gerando um campo representacional, tornando familiar algo desconhecido para um dado grupo social.

A sexualidade neste estudo é compreendida sob dois pontos de vista. 0 primeiro sugere uma compreensão metafórica, portanto reprimida, negada, controlada, vigiada e devidamente punida $^{6}$. 0 segundo compreende uma hipérbole contrapondose à repressão e à negação amplamente divulgada por meio da estratégia de interdição das estruturas organizacionais e 
institucionais da sociedade, a qual é evidenciada na ampla penetração da esfera pública como meio de controle na esfera privada? .

0 modo como o corpo tem sido visto e avaliado por várias eras e culturas representa uma história das mensagens sexuais transmitidas pelos mitos sociais e pelos costumes baseados em mitos ${ }^{6}$, pois o corpo apresenta um importante simbolismo cultural que tem fortes implicações com a sexualidade.

Dessa compreensão metafórica, a sexualidade se configura na dimensão do mito. A história da influência exercida pela mitologia em nossas idéias acerca do corpo prossegue ao longo dos séculos. No início deste século, a introdução de uma 'mitologia social', derivada do capitalismo e baseada na auto-satisfação, deu origem, gradativamente, a uma forma de consumismo em que 0 corpo é, ao mesmo tempo, máquina e mercadoria ${ }^{6}$.

A sexualidade como elaboração histórica foi imposta pelo puritanismo moderno nas formas de interdição, inexistência e mutismo ${ }^{7}$. Sugere-se que a hipótese repressiva foi responsável pelo incitamento ao discurso sobre o sexo, de uma forma progressiva, através da disseminação e implantação daquilo que foi considerado como sexualidade polimorfa?

A sexualidade se configura numa perspectiva histórica na esfera do poder. Assim, o poder institucional não se utiliza da proibição como um fato acabado, mas estabelece nos discursos sobre sexo o aspecto da utilidade pública, criando uma rede de observações. Tem-se como ponto de partida as análises das condutas sexuais, suas determinações e efeitos nos limites entre o biológico e o econômico e, sobretudo, entre o Estado e o indivíduo ${ }^{7}$.

$\mathrm{Na}$ enfermagem, o cuidado para manter seus doentes separados sexualmente, mediante o discurso de proteção, conforto e segurança, faz com que sejam conservados sob a guarda constante do olhar da equipe de enfermagem, representado pelo comando do profissional enfermeiro ${ }^{1}$.

Há um policiamento enorme do desejo de todos, estes 'assexuados' que mentem que não sentem, mesmo explodindo discursivamente sobre 0 tema da sexualidade ${ }^{8}$. Aponta uma clara referência à não-instrumentalização dos profissionais de enfermagem, no tocante ao assunto, reveladora da própria dificuldade para manejar sua sexualidade.

A atuação da enfermagem psiquiátrica e a prática do enfermeiro consistem em vigiar continuamente o paciente, medicá-lo, mantêlo amarrado e despido. Estas práticas são equivalentes porque se inscrevem no hospital psiquiátrico como a contrapartida prática à responsabilidade 'técnica' e 'legal' que a sociedade e a família Ihe conferem, e que é continuamente lembrada pelos dirigentes da instituição ${ }^{9}$. De outra forma, encerram a situação de censura sobre 0 assunto estabelecendo uma situação limítrofe para 0 portador de transtorno mental.

A prática discursiva e a interface entre a textualidade e o grupo social de pertença são constitutivos de uma mesma coisa, na medida em que o autor neste contexto é o personagem do discurso, o qual por sua vez tem uma função social. Portanto, o profissional enfermeiro é o personagem que exerce a política do silêncio, negando a sexualidade do portador de transtorno mental, mesmo que para este autor a noção de negação seja considerada ambígua ${ }^{13}$.

Uma formação discursiva não é uma doutrina, mas um dispositivo que institui ao mesmo título e em um mesmo movimento o conjunto das condições de sua enunciação e do que anuncia. Ao ressaltar a articulação entre o discurso e a sociedade, observa-se que existe há muito tempo uma propensão em considerar a sociedade como a superposição de um alicerce econômico, das classes sociais, e de falas destinadas a traduzir, representar, inverter, negar, deslocar esta realidade já constituída pelo sentido e a linguagem, não se superpondo nas relações econômicas e sociais, mas consistente numa dimensão fundante dessas relações ${ }^{13,14}$.

\section{APRESENTAÇÃO E DISCUSSÃO DOS RESULTADOS}

0 processo de seleção e classificação do material coletado considerou cada resposta sobre o desenho da Técnica de Investigação em Situação Cotidiana (TSC), associando imagens a frases ${ }^{1}$, na perspectiva de uma entrevista, tais como: 0 Banho 1, A Surpresa, 0 Banho 2, 0 Olhar, 0 Banho 3 e A Dança. Portanto, representou o instrumento de coleta de dados a partir de seis pranchas de um conjunto de 16 , por serem os mais significativos sobre 0 objeto do estudo, exemplificados na Figura 1.

Figura 1:

Cartilha Técnica de Investigação em Situações Cotidianas (TSC).

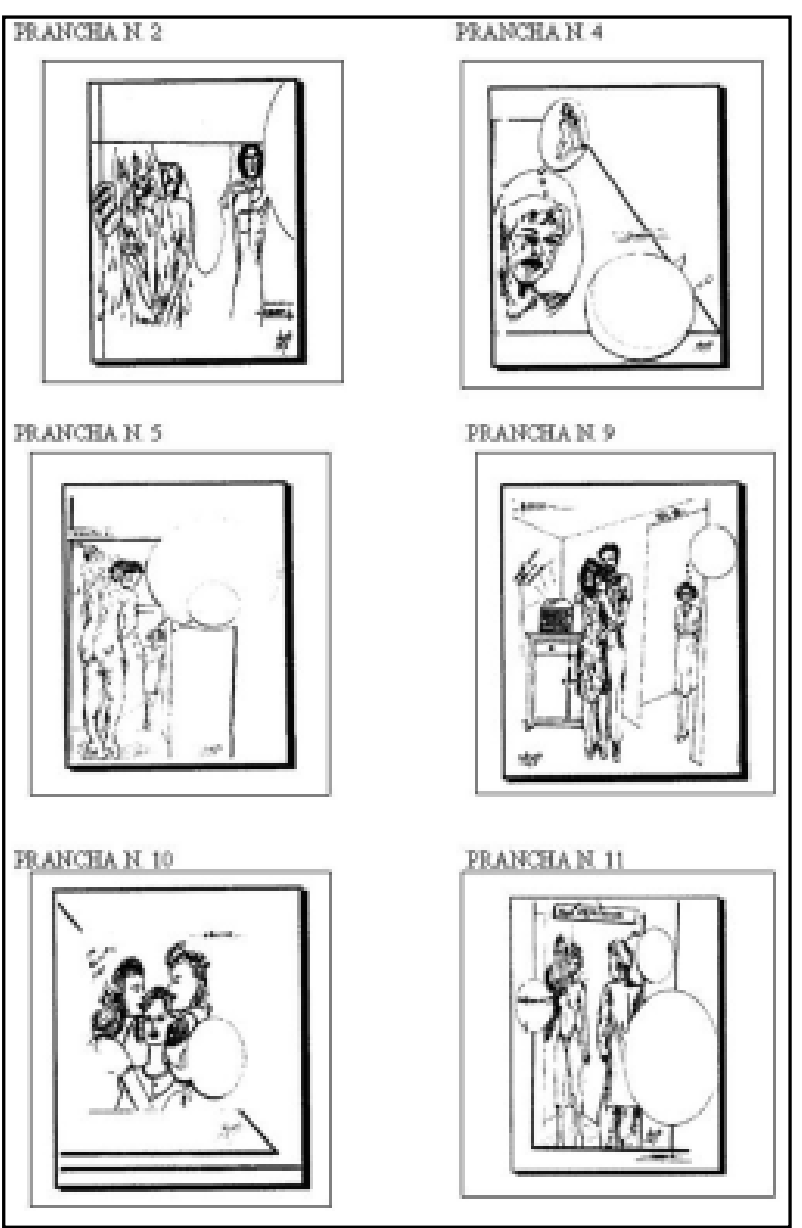

A coleta dos dados foi realizada em cinco instituições públicas que prestavam assistência ao portador de transtorno mental, no município de Ribeirão Preto-SP, totalizando 17 enfermeiros entrevistados, respeitados os preceitos éticos emanados da Resolução 196/1996/CNS e do parecer do Comitê de Ética da EERP/USP. 
A análise e a interpretação iniciaram-se mediante leitura flutuante, buscando-se a apreensão das unidades de entrevistas expressas nas manifestações discursivas não conceituais, especialmente os significados indicativos das ações, ou seja, os verbos e suas freqüências em todas as entrevistas para cada desenho.

Finalmente, as unidades das entrevistas foram agrupadas a partir de uma temática emergente e interpretadas à luz da TRS, focalizando-se o espaço interacional que diz respeito à informação circulante sobre a sexualidade do portador de transtorno mental através da pressão à inferência, do engajamento e da dispersão da informação sobre um dado objeto social? .

A TSC, enquanto recurso técnico-metodológico, foi construída para apreender as representações sociais no cotidiano do profissional enfermeiro, especialmente os temas revestidos de tabus, normatizações, estigmas e preconceitos exemplificados pela sexualidade do portador de transtorno mental diante do discurso de conforto, segurança e proteção do profissional enfermeiro. É uma proposta para abordagem dos sujeitos considerada alternativa ante os modelos tradicionais da investigação $0^{10,11}$.

Apresenta-se em forma de "cartilha", possibilitando a apreensão de opiniões, valores, símbolos, imagens e saberes teóricos e do senso comum sobre o cotidiano da enfermagem psiquiátrica no transcurso de uma jornada de trabalho, na medida em que os personagens envolvidos situam-se na mesma dimensão do questionamento pretendido $0^{10,11}$.

0 sujeito entrevistado expressa-se complementando o diálogo sugerido, respondendo o que falaria nas circunstâncias da cena, e o que imaginaria sobre a mesma. Estas alternativas oferecem mais possibilidades para o investigado expressar-se sobre cada cena, conforme sua livre escolha, quer seja verbalizando situações vividas e/ou relatadas, quer seja imaginando e assinalando com um X no canto inferior direito de cada página ${ }^{10,11}$.

Como dimensão e estratégia metodológica, a TRS permite apreender a inter-relação entre conteúdo, objeto e sujeito, explicar e descrever um conhecimento compartilhado, o vínculo afetivo, sob certa pressão, focalização e dispersão da informação pelos sujeitos psicossociais.

0 profissional enfermeiro reconhece a temática deste estudo nas pranchas em que a sexualidade do portador de transtorno mental se apresenta mais ou menos explicitada, através de estímulo visual, numa seqüência de cenas que retratam o cotidiano de sua inserção profissional e suas práticas discursivas, negando-a ${ }^{1,10}$.(Quadro 1).

A compreensão da sexualidade do portador de transtorno mental distingue-se através de dois tipos de negação: uma chamada polêmica, a outra descritiva. A primeira descreve um estado de coisa em que seu enunciado pode ser parafraseado com o auxílio de um enunciado positivo e que serve para falar do mundo. A segunda tem um funcionamento diferente da anterior, pois contesta, opõe-se a uma asserção anterior, explícita ou não. Trata-se de um verdadeiro ato de negação, de refutação do enunciado positivo correspondente ${ }^{13}$. Exemplificando-as:

Não precisa dois tomar banho debaixo do mesmo chuveiro (E5).

\section{É 'normal' que pense em sexo (E1).}

A circulação de uma dada informação nem sempre é claramente definida e, na maioria das vezes, torna-se ambígua e imprecisa ${ }^{15}$. Desse entendimento, foi preciso desarticular os discursos dos sujeitos pesquisados, decompondo-os, para deixar emergir o termo e/ou vocábulo empregado em seu interior, como indicativo de um ato de intenção sobre esse extrato mais profundo do discurso, ou seja, o silenciamento sobre o assunto.

Nessa perspectiva, o silenciamento sobre um dado assunto torna-se hábito. Este traduz a experiência, pela qual tudo, até o insólito, torna-se costumeiro e banalizado. 0 poder de conhecimento e de aceitação atribuído ao simples fato de ver apenas será compreendido se admitida que essa experiência seja socialmente codificada. Aprende-se a ver ou a não ver, a não prestar atenção àquele que sempre viveu no meio dessas pessoas, sempre em contato com elas, recebendo do seu ambiente, logo de saída, as regras de um saber-viver-com ${ }^{16}$.

Em sua prática diária diante da questão da sexualidade, embora negada, o profissional enfermeiro apresenta uma preocupação, um anseio e uma necessidade de "conversar", "falar", "comunicar", "pedir", "perguntar", "saber" sobre a sexualidade do portador de transtorno mental, extrapolando a circunscrição do mesmo, por ser assunto censurado e, ao mesmo tempo, entendido como silenciado no interior institucional, circunscrito à esfera do trabalho da enfermagem, mediado pelo discurso de segurança, conforto e proteção.

Quadro 1:

Construção Gráfica do Corpo e sua Mensagem

\begin{tabular}{|c|c|c|c|}
\hline PRANCHA & ASSUNTO & SUBMERGENTE & CONSTRUÇÃO \\
\hline N. 02 & "O Banho 1..." & Homossexualismo Masculino & $\begin{array}{l}\text { - Exposição parcial / Focalizando tronco e } \\
\text { cabeça / Plano anterior }\end{array}$ \\
\hline N. 04 & "A Surpresa..." & Fantasia sexual & $\begin{array}{l}\text { - Corpo / Face / Focalizando a expressão } \\
\text { facial /Plano anterior }\end{array}$ \\
\hline N. 05 & "0 Banho 2..." & Auto-erotismo [masturbação] & $\begin{array}{l}\text { - Exposição parcial do corpo masculino / } \\
\text { Plano posterior }\end{array}$ \\
\hline N. 09 & "A Dança..." & Interação Física & $\begin{array}{l}\text { - Focalizando o corpo vestido / Plano ântero- } \\
\text { posterior }\end{array}$ \\
\hline N. 10 & "O Olhar..." & Homossexualismo Feminino & - Face / Focalizando o olhar / Plano lateral \\
\hline N. 11 & "O Banho 3..." & Erotismo & $\begin{array}{c}\text { - Parcialmente desnudo / Focalizando o corpo } \\
\text { feminino / Plano anterior }\end{array}$ \\
\hline
\end{tabular}


Tomado de empréstimo o questionamento ${ }^{16}$, pergunta-se: 0 que está em jogo por trás dessa codificação? Constitui-se um saber sutil pela presença multiforme e incessante da loucura, em que "o indivíduo tira do saber-fazer do grupo as formas do seu controle, para modelar para si uma experiência congruente com a do seu ambiente social, e expressar-se em consonância com ele" 16:96. Assim, foi a intenção desse reolhar os dados sobre a sexualidade do portador de transtorno mental na perspectiva do discurso do profissional enfermeiro (Quadro 2).
Os vocábulos detectados reforçam a intenção na direção de atos da própria comunicação, privilegiando a verbalização sobre essa questão que também pode ser entendida na esfera da dialogicidade. Esta, por ser uma condição sine qua non da mente humana, diz respeito à capacidade humana de conceber, criar e comunicar realidades sociais ${ }^{17}$. Dessa forma, entende-se que tem a finalidade de evocar esclarecimentos que franqueiem o profissional enfermeiro a falar, conversar e saber algo mais sobre essa negação consensual, censurada e estabelecida pelas normas

Quadro 2

Listagem dos vocábulos expressos pelo enfermeiro com intenção à comunicação

\begin{tabular}{|c|c|c|c|c|c|}
\hline \multirow{2}{*}{$\begin{array}{l}\text { Listagem dos } \\
\text { "conversar" }\end{array}$} & \multirow{2}{*}{$\begin{array}{c}\text { vocábulos expr } \\
\text { E1; E4; E2; E2; } \\
\text { E4; E2; }\end{array}$} & \multicolumn{2}{|c|}{ pressos pelo enfermeiro com } & \multicolumn{2}{|c|}{ intenção à comunicação } \\
\hline & & "orientar" & E1 & "perguntar-lhe" & E1 \\
\hline "conversaremos" & E3 & "falar" & $\mathrm{E} 7 ; \mathrm{E} 2 ; \mathrm{E} 1$ & "chamar" & E4 \\
\hline "converse" & E2 & "falavam" & E2 & "pedir" & $\mathrm{E} 1 ; \mathrm{E} 8$ \\
\hline "foi orientado" & E1 & $\begin{array}{c}\text { "vou ver" } \\
\text { [falar / conversar] }\end{array}$ & E3 & "chame" & E2 \\
\hline "orientações" & E2 & "vou saber" & E2 & "se comunicar" & E1 \\
\hline "orientá-lo" & E8 & $\begin{array}{c}\text { "me dizer" } \\
\text { [falar / conversar] }\end{array}$ & $\mathrm{E} 5$ & $\begin{array}{c}\text { "prevenir" } \\
\text { [falar/conversar] }\end{array}$ & E3 \\
\hline
\end{tabular}

sociais, como também silenciada, formando um conjunto significativo na esfera do não-dito para dar à negação da sexualidade seu caráter polissêmico e polêmico.

Concorda-se que, sobre a sexualidade do portador de transtorno mental, é preciso fazer um desvio tão grande do confronto dos prováveis gestos indicativos das manifestações da sexualidade que a inquietação suscita a reticência em falar disso ${ }^{16}$.

A informação emanada de cada uma das cenas analisadas demonstra que o enfermeiro, ao confrontar-se a partir da sua experiência pessoal com a sexualidade, adota uma decisão de interdição, afastamento, negação, omissão, situada ao nível social e interacional. Dito de outra forma, a informação sobre a sexualidade está ancorada na experiência pessoal e, concomitantemente, objetivada a partir da pressão, inferência e engajamento da informação que revela um sentido de economia discursiva, por situarse na esfera do silenciamento, ou seja, do não-dizível².

Organizaram-se os vocábulos para compreender o sentido de economia atribuído pelos enfermeiros em suas manifestações discursivas. Portanto, evidenciou-se na estruturação desse discurso um esquema elementar, monossilábico, mas que não atende por si só aos apelos dos determinantes psicossociais, mas às imagens e significados historicamente construídos sobre a loucura e a sexualidade do portador de transtorno mental.

0 enfermeiro, respaldado pela lógica situacional, responde ao estímulo da TSC conferindo um sentido e um significado para a cena, verbalizando e/ou silenciando. Dessa forma, interage mecanicamente com o outro, o portador de transtorno mental e a sua loucura, ou seja, eu e o outro, este diferente de mim, que me incomoda e aflige por ser objeto do meu agir profissional. Assim, exerce sua capacidade discursiva para definir o espaço da sua intervenção, legitimando seu poder no confronto com a ilegitimidade da sexualidade.
A apreensão da fragmentação como recurso de análise, tomada no campo do signo lingüístico, revela a intenção de esclarecer as dificuldades e limitações do enfrentamento cotidiano dessa questão. Um signo lingüístico é motivado por uma palavra, pois evoca as partes que o compõem e outras que lhe são associadas ${ }^{2}$ até o processo de familiarização. Este fato evidencia que

as representações sociais não surgem do raciocínio absoluto ou do processamento das informações, mas do legado adquirido do passado, da cultura, das tradições e da linguagem inseridos num sistema de crenças compartilhadas socialmente pelo grupo de pertença ${ }^{13: 12}$.

É, portanto, esta a atitude orientadora de sentido, cuja finalidade se reveste de praticidade, enquanto entendimento da cotidianeidade desses sujeitos psicossociais, em que a compreensão do ocultamento, também entendido como silenciamento sobre a sexualidade do portador de transtorno mental, remete à visão de um resumo. Este só é possível se reunir o que se diz em fragmentos e em fugitivas pinceladas da linguagem ${ }^{16}$.

Se de um lado existe o silenciamento em forma de ocultamento sobre um saber-fazer, de outro, entende-se que há pressão, focalização e dispersão da informação sobre a sexualidade na atuação do profissional enfermeiro, mesmo que estes dados sejam polissêmicos, ambivalentes, múltiplos, simultaneamente insuficientes e superabundantes. Estes dados intentam dar respostas para cada uma das situações, o que de certa maneira remete à esfera do inculto, pois diante de certos problemas todo indivíduo é inculto? ${ }^{2}$.

A condição de inculto, nesse estudo, não atende de forma literal à dimensão do termo, uma vez que todos os entrevistados são detentores de formação acadêmica. Atende à condição inserida na ordem do silenciamento, do não-dito por já estar embutido no manuseio da questão, algo que prescinde do dizível, 
estando circunscrito na "estandartização" das normas, dos valores e das crenças.

0 profissional enfermeiro utiliza seu modo particular para se posicionar sobre a sexualidade, silenciando-a ou censurando-a, por ser um fato aparente, conforme exemplos a seguir, codificados mediante a instituição $\left(\mathrm{I}_{1,2,3,4}\right)$, o profissional enfermeiro $(\mathrm{E})$ e a manifestação discursiva (vivida-V, relatada- $R$, ou imaginada-I pelo entrevistado), podendo ocorrer mais de uma resposta:

Talvez, precisarei prevenir esses dois quanto a possíveis intercorrências $\mathrm{I}_{2} . \mathrm{E}_{3}(\mathrm{~V})$

Vamos mais depressa com esse banho, pois o café já está sendo servido e se não ir logo, poderá ficar sem o desjejum. Nossa!! I ${ }_{2} \cdot \mathrm{E}_{3}(\mathrm{R})$

Nessa situação não sei o que falar. $\mathrm{I}_{4} \cdot \mathrm{E}_{1}(\mathrm{R}) /(\mathrm{I})$

Émuito difíil lidar com a sexualidade. Nesse caso eu dei sorte, pois ele guardou e acatou a minha orientação. $\mathrm{I}_{3} \cdot \mathrm{E}_{1}(\mathrm{~V}) /(\mathrm{R})$

Tinha que ser agora! Depois eu volto. $\mathrm{I}_{1} . \mathrm{E}_{4}(\mathrm{I})$

Por conseguinte, circunscreve a negação na imprecisão do exercício profissional. No espaço da sua atuação, esse profissional nega, pois somente dessa forma lhe é possível compartilhar desse assunto e assim indicar o grau de envolvimento sobre o mesmo. A focalização da informação é representada e compreendida com certo grau de distanciamento e implicação em relação ao objeto social. Estes variam com a interação social a partir dos próprios juízos e opiniões².

Através da manifestação discursiva, verificou-se que o profissional enfermeiro nega a sexualidade do portador de transtorno mental, circunscrevendo-a ao rol dos desvios, transgressões e doença ${ }^{1}$. Ao negar, adota uma posição de afastamento, uma atitude ora repressiva, ora não repressiva e/ou defensiva, e ao fazê-lo ancora e objetiva nas figuras e significados ${ }^{2}$ construídos historicamente sobre a loucura numa concepção fantasmática ${ }^{19}$.

Tal posicionamento revela a estratégia adotada sobre esse saber e poder, a qual cumpre as determinações do seu estatuto profissional, indo ao encontro das expectativas institucionais e sociais. Os elementos do saber-fazer, do não-dito, do indisível ${ }^{3}$ revelam o campo figurativo como uma zona inscrita no silenciamento sobre as manifestações da sexualidade.

\section{Referências}

1. Miranda FAN. Doente mental: a sexualidade negada. [dissertação de mestrado]. Ribeirão Preto (SP): Escola de Enfermagem/USP; 1997.

2. Moscovici SA. A representação social da psicanálise. Rio de Janeiro (RJ): J Zahar; 1978.

3. Orlandi EP. As formas do silêncio: no movimento dos sentidos. $5^{a}$ ed. Campinas (SP): Ed. UNICAMP; 2002.

4. Giffin K. Violência de gênero, sexualidade e saúde. Cad Saude Publica 1994; 10 (supl. 1): 146-56.

5. Schilder P. A imagem do corpo: as energias da psique. $3^{\mathrm{a}}$ ed. São Paulo (SP): Martins Fontes; 1999.

6. Highwater J. Mito e sexualidade. São Paulo (SP): Saraiva; 1992.

7. Foucault M. História da sexualidade, 1. A vontade de saber. $14^{\mathrm{a}} \mathrm{ed}$. Rio de Janeiro(RJ): Graal; 2001.

\section{CONSIDERAÇÕES FINAIS}

No cotidiano, o profissional enfermeiro é solicitado, dentre suas atribuições profissionais, a emitir opiniões, julgamentos, prestar informações sobre algo que se apresenta como demandas de sua prática ${ }^{18}$, Estas são oriundas da reificação do conhecimento científico e da consensualidade do senso comum, uma vez que os sujeitos psicossociais objetos da sua atuação são pessoas relacionais, psicodinâmicas e concretas e, portanto, exigem do mesmo a condição de estar apto a dar respostas eficazes, efetivas e eficientes aos problemas confrontados.

A análise do discurso foi empregada como possibilidade de captar as manifestações discursivas capazes de produzir realidades sobre o uso de conceitos expressos em linguagem verbal, icônica e gestual, dando sentido ao mundo sobre a sexualidade do portador de transtorno mental.

Entende-se que a negação da sexualidade sob a luz da Teoria TRS é, ao mesmo tempo, um processo e um produto de elaboração simbólica intermediada pela linguagem, com ênfase no silêncio, ou seja, na relação dito/não dito como forma de silenciamento sobre um saber-fazer não aclarado, enquanto campo da atuação profissional e sua relação dialógica.

Ambos, silêncio e silenciamento, são articulados na trama diária do profissional enfermeiro, requerendo um constante reequilíbrio diante das respostas que se situam entre a ciência e o senso comum sobre a sexualidade do portador de transtorno mental. 0 reequilíbrio gera conflitos.

Concorda-se que o conflito implica uma ambigüidade e ocorre entre a percepção da realidade e do contradesejo que leva a negar sua percepção ${ }^{19}$. Dessa forma, torna-se um artifício social compartilhado que dá sentido e orientação ao seu modus operandis e modus vivendis, como uma teoria implícita do não-dizível, porque somente o fragmento desta questão, ou seja, a sexualidade do portador de transtorno mental, poderia escapar em suas manifestações discursivas. Com auxílio de um mecanismo particular, o profissional enfermeiro desmente a evidência da percepção ao negar e reconhece a realidade da sexualidade do mesmo, tornando um objeto inapreensível em sua prática cotidiana.

8. Miranda MCL. 0 parentesco imaginário: história e representação social da loucura nas relações do espaço asilar. São Paulo (SP): Cortez; 1994.

9. Fraga MNO. A prática de enfermagem psiquiátrica: subordinação e resistência. São Paulo (SP): Cortez; 1993.

10. Miranda FAN, Furegato ARF. Percepções da sexualidade do doente mental pelo enfermeiro. Rev Latino-am Enfermagem 2002 mar/abr; 10(2): 207-13.

11. Miranda FAN, Furegato ARF. Instrumento projetivo para estudos de representações sociais na saúde mental. Vivência UFRN/CCHLA 2007; 32: 293-302.

12. Miranda FAN, Furegato ARF. Construção de um instrumento projetivo para estudo em representações sociais. SMDA: rev eletr saude mental, alcool e drogas [periódico on-line] 2005; [citado 10 jan 2007]; 2(1): 1-14. Disponível em: http://www2.eerp.usp.br/ resmad/artigos/2006v2n1a06.pdf 
13. Maingueneau D. Gêneses du discours. Bruxelas(BE): Mardaga; 1984.

14. Maingueneau D. Novas tendências em análise do discurso. Campinas (SP): Pontes; 1994.

15. Vala J, Monteiro MB. Psicologia social. Lisboa(PT): Fundação Calouste Gulbenkian; 1993.

16. Jodelet D. Loucuras e representações sociais. Petrópolis(RJ): Vozes; 2005.
17. Marková I. Dialogicidade e representações sociais: as dinâmicas da mente. Petrópolis(RJ): Vozes; 2006.

18. Miranda FAN, Ardaia AR, Araújo KL. 0 cotidiano da enfermagem psiquiátrica no hospital geral: perspectiva dos profissionais de saúde. Cient Cienc Biol Saúde 2000 out; 2(1): 47-63.

19. Agamben G. Estâncias: a palavra e o fantasma na cultura ocidental. Belo Horizonte(MG): Ed UFMG; 2007. 